\title{
Diferentes fontes proteicas em rações de leitões sobre atividade da tripsina e parâmetros sangüíneos
}

\author{
Maria Cristina THOMAZ \\ Melissa Izabel HANNAS ${ }^{2}$ \\ Fernanda Marcussi $\mathrm{TUCCl}^{3}$ \\ Antônio João \\ SCANDOLERA ${ }^{4}$ \\ Maria Marta LODDI ${ }^{5}$ \\ Fábio Enrique Lemos \\ BUDIÑO ${ }^{6}$
}

\section{Correspondência para: \\ Profa. Dra. Maria Cristina Thomaz, UNESP - FCAV Departamento de Zootecnia, Via de acesso Prof. Donato Castellane, s/n, Jaboticabal/SP, 14884-900, thomaz@fcav.unesp.br}

Recebido para publicação: 10/04/2008 Aprovado para publicação: 30/10/2008

\author{
1 - Departamento de Zootecnia da Faculdade de Ciências Agrárias e \\ Veterinárias da Universidade Estadual Paulista, Jaboticabal - SP \\ 2 - Alltech do Brasil, Curitiba - PR \\ 3 - MAPA, Brasília - DF \\ 4 - Universidade Federal do Paraná, Curitiba - PR \\ 5 - Universidade Estadual de Ponta Grossa, Ponta Grossa - PR \\ 6 - Instituto de Zootecnia/APTA/SAA, Nova Odessa - SP
}

\section{Resumo}

Foram utilizados 64 leitões, submetidos a oito tratamentos: ração com leite em pó (LP), três rações com níveis crescentes de plasma suíno (PS), três rações com níveis crescentes de ovo inteiro (OI) e ração com alto nível de farelo de soja (FS). Foi coletado sangue dos animais aos 27 e 34 dias de idade para avaliação dos parâmetros sangüíneos, e aos 28 e 35 dias de idade quatro animais por tratamento foram abatidos para coleta do pâncreas e posterior determinação do peso absoluto (PA) e peso relativo (PR) do pâncreas e da atividade da tripsina (AT). Os tratamentos não influenciaram significativamente $\mathrm{O}$ PA e a AT. Verificou-se efeito significativo dos níveis crescentes de PS, com redução linear dos leucócitos e aumento do volume globular, aos 27 dias; enquanto aos 34 dias, observou-se aumento linear das hemácias. Aos 27 dias, os animais arraçoados com níveis de PS apresentaram menor percentagem de eosinófilos do que aqueles arraçoados com níveis de OI. A utilização de plasma suíno promoveu menor estímulo à resposta imune, enquanto que a utilização de ovo inteiro promoveu maior resposta humoral dos leitões.

\section{Introdução}

As rações contendo lactose e proteínas de origem animal como plasma, hemácias ${ }^{1}$ e ovo $^{2}$, podem diminuir a gravidade dos efeitos nutricionais impostos pelo desmame. A utilização de plasma sangüíneo na ração de leitões exerce efeito positivo sobre o desempenho animal, mucosa intestinal e imunidade dos leitões. ${ }^{3}$ Estes efeitos podem estar relacionados ao estímulo direto do consumo de ração, às alterações na secreção de enzimas digestivas, a preservação da imunidade dos animais e a menor incidência de diarréia.

Segundo Makkink et al. ${ }^{4}$ a fonte de proteína na ração de leitões na desmama interfere no consumo de ração, ganho de peso, digestibilidade do nitrogênio e atividade de enzimas pancreáticas, podendo estes fatores estar inter-relacionados ou não.

Especialmente nos suínos, o estresse provocado por ocasião da desmama determina respostas fisiológicas e metabólicas podendo alterar o padrão sangüíneo normal. Determinados nutrientes e substâncias presentes nas rações também podem interferir nestas respostas ou estimular respostas inflamatórias, em virtude da presença de fatores antinutricionais e ou alergênicos; ao contrário, outros elementos ou presença de imunoglobulinas podem favorecer a manutenção do estatus sanitário animal, melhorando a defesa do organismo.

Coffey e Cromwell ${ }^{5}$ verificaram que o plasma animal interfere positivamente no desempenho dos leitões após desmama, por melhorar a imunocompetência, devido à presença das imunoglobulinas. A existência de imunoglobulinas no ovo também pode 
exercer efeito positivo sobre a imunidade dos animais ${ }^{6}$, enquanto a utilização de farelo de soja, por conter fatores alergênicos, estimula a respostas inflamatórias no organismo animal ${ }^{4}$.

O plasma animal fornecido na ração de leitões pode reduzir a incidência ou a gravidade da diarréia pós-desmama ${ }^{3}$. Segundo Coffey e Cromwell ${ }^{5}$, as imunoglobulinas presentes no plasma podem prevenir os danos causados por bactérias e vírus sobre a parede intestinal, reduzindo a ocorrência de diarréia.

O objetivo do presente trabalho foi avaliar a atividade da enzima tripsina e o peso do pâncreas, e os parâmetros sangüíneos em leitões recém-desmamados consumindo rações com diferentes fontes de proteína, no período de 21 a 27 e de 21 a 34 dias de idade.

\section{Material e Método}

Foram utilizados 68 leitões mestiços (quatro abatidos no desmame e 64 ao longo do experimento) e desmamados aos 21 dias de idade. Os animais foram alojados em dois galpões de alvenaria, contendo cada um 36 baias individuais equipadas com bebedouro tipo vaso comunicante e comedouro semiautomático.

As rações experimentais, fornecidas à vontade, foram formuladas para atenderem ou excederem as recomendações do National Research Council ${ }^{7}$, sendo isoprotéicas, isolisínicas, devidamente suplementadas com minerais e vitaminas.

Foram utilizadas oito rações (Tabela 1), sendo uma controle positivo e outra negativo, contendo, respectivamente, leite em pó desnatado (LP) e farelo de soja (FS) como principal fonte de proteína, três rações com níveis crescentes de plasma suíno (PS) e três rações com níveis crescentes de ovo inteiro (OI). O PS foi incluído nas rações, substituindo 25,50 e $75 \%$ da proteína do leite da ração LP, enquanto o OI foi incluído nas rações substituindo 15, 30 e 45\% da proteína do leite em pó da ração LP.

Para a avaliação do peso do pâncreas e da atividade da tripsina, os leitões foram abatidos em duas épocas, aos 28 e 35 dias de idade (sete e 14 dias pós-desmama), sendo quatro repetições por tratamento em cada abate. Um grupo adicional de quatro leitões foi abatido no momento da desmama, aos 21 dias de idade, sendo coletadas amostras do pâncreas que corresponderam ao grupotestemunha.

Após o abate foi retirado e pesado o pâncreas, sendo as amostras armazenadas em nitrogênio líquido a $-70^{\circ} \mathrm{C}$. A atividade da tripsina foi determinada segundo a metodologia descrita por Kakade et al..$^{8}$ e a concentração de proteína do pâncreas foi determinada pelo método descrito por Hartree?

Foram coletadas amostras de sangue a desmama, aos 27 dias e aos 34 dias de idade. As amostras de soro ou plasma foram analisadas imediatamente ou congeladas para análise posterior no Laboratório de Patologia Clínica do Hospital Veterinário da FCAV - UNESP.

Através de hemograma e leucograma, foram determinadas as concentrações de hemácias $\left(\mathrm{mm}^{3} \times 10^{3}\right)$, leucócitos $\left(\mathrm{mm}^{3}\right)$, hemoglobina $\left(\mathrm{g}^{\mathrm{\%}} \mathrm{)}\right)$, o volume globular $(\%)$ e realizada a contagem diferencial de leucócitos, calculando-se as percentagens de basófilos, eosinófilos, neutrófilos, linfócitos e monócitos. As proteínas plasmáticas foram quantificadas através do proteinograma (Kit Eletroforese), determinando-se a proteína total e a albumina em $\mathrm{g} / \mathrm{dL}$.

Para as análises estatísticas, o tratamento controle LP foi considerado como nível $0 \%$ de PS e nível $0 \%$ de OI, possibilitando a decomposição de oito contrastes $(\mathrm{C})$ ortogonais: $\mathrm{C} 1=$ farelo de soja vs demais tratamentos; C2= níveis de PS vs níveis de OI; C3= regressão linear do PS; C4= regressão quadrática do PS; C5= regressão cúbica do PS; C6 = regressão linear do $\mathrm{OI} ; \mathrm{C} 7=$ regressão quadrática do $\mathrm{OI}$ e C8 = regressão cúbica do OI.

Para as avaliações do peso do pâncreas e da atividade da tripsina, foi utilizado delineamento em blocos casualizados, em esquema fatorial com duas 
Tabela 1 - Composição centesimal e calculada das rações experimentais

\begin{tabular}{|c|c|c|c|c|c|c|c|c|}
\hline Ingredientes & LP & $\begin{array}{c}\text { PS } \\
25 \% *\end{array}$ & $\begin{array}{c}\text { PS } \\
50 \% *\end{array}$ & $\begin{array}{c}\text { PS } \\
75 \% *\end{array}$ & $\begin{array}{c}\mathrm{OI} \\
15 \% *\end{array}$ & $\begin{array}{c}\text { OI } \\
30 \% *\end{array}$ & $\begin{array}{c}\text { OI } \\
45 \% *\end{array}$ & FS \\
\hline Leite em pó & 23,502 & 17,474 & 11,433 & 5,300 & 20,485 & 17,468 & 14,452 & 8,743 \\
\hline Plasma suíno & - & 2,950 & 5,906 & 8,940 & - & - & - & - \\
\hline Ovo inteiro & - & - & - & - & 2,540 & 5,080 & 7,620 & - \\
\hline Lactose & 2,343 & 5,483 & 8,629 & 11,83 & 3,914 & 5,485 & 7,056 & 10,030 \\
\hline Milho & 43,106 & 43,46 & 43,813 & 44,00 & 40,962 & 38,818 & 36,675 & 38,413 \\
\hline Calcário & 0,092 & 0,495 & 0,899 & 1,300 & 0,120 & 0,148 & 0,176 & 0,124 \\
\hline D1-metionina & 0,225 & 0,242 & 0,259 & 0,276 & 0,203 & 0,182 & 0,161 & 0,264 \\
\hline Fosfato bicálcico & 1,769 & 1,412 & 1,054 & 0,720 & 1,851 & 1,932 & 2,013 & 2,213 \\
\hline Inerte (Caulim) & 1,100 & 0,970 & 0,840 & 0,820 & 2,059 & 3,017 & 3,974 & - \\
\hline L-lisina $\mathrm{HCl}$ & 0,391 & 0,413 & 0,435 & 0,460 & 0,398 & 0,405 & 0,412 & 0,511 \\
\hline L-treonina & 0,206 & 0,200 & 0,194 & 0,187 & 0,203 & 0,201 & 0,198 & 0,251 \\
\hline L-triptofano & 0,027 & 0,017 & 0,007 & 0,000 & 0,029 & 0,031 & 0,033 & 0,032 \\
\hline Sal & 0,330 & 0,200 & 0,071 & 0,000 & 0,355 & 0,381 & 0,407 & 0,573 \\
\hline Açúcar & 1,000 & 1,000 & 1,000 & 1,000 & 1,000 & 1,000 & 1,000 & 1,000 \\
\hline Antioxidante & 0,040 & 0,040 & 0,040 & 0,040 & 0,040 & 0,040 & 0,040 & 0,040 \\
\hline Farelo de soja & 18,00 & 18,00 & 18,00 & 18,00 & 18,00 & 18,00 & 18,00 & 30,00 \\
\hline Suplem. vitam. ** & 0,600 & 0,600 & 0,600 & 0,600 & 0,600 & 0,600 & 0,600 & 0,600 \\
\hline Suplem. mineral $* * *$ & 0,240 & 0,240 & 0,240 & 0,240 & 0,240 & 0,240 & 0,240 & 0,240 \\
\hline Óleo vegetal & 6,000 & 6,000 & 6,000 & 6,000 & 6,000 & 6,000 & 6,000 & 6,000 \\
\hline Óxido de zinco & 0,220 & 0,220 & 0,220 & 0,220 & 0,220 & 0,220 & 0,220 & 0,220 \\
\hline Carbonato de sódio & 0,811 & 0,585 & 0,359 & 0,069 & 0,781 & 0,752 & 0,723 & 0,746 \\
\hline Total & 100,0 & 100,0 & 100,0 & 100,0 & 100,0 & 100,0 & 100,0 & 100,0 \\
\hline \multicolumn{9}{|l|}{ Composição calculada } \\
\hline $\mathrm{EM}(\mathrm{kcal} / \mathrm{kg})$ & 3.500 & 3.500 & 3.500 & 3.495 & 3.500 & 3.500 & 3.500 & 3.444 \\
\hline Proteina (\%) & 20,50 & 20,50 & 20,50 & 20,51 & 20,50 & 20,50 & 20,50 & 20,50 \\
\hline Fibra (\%) & 2,192 & 2,184 & 2,175 & 2,163 & 2,136 & 2,081 & 2,026 & 2,833 \\
\hline Gordura (\%) & 7,925 & 7,953 & 7,981 & 8,002 & 8,653 & 9,382 & 10,11 & 7,903 \\
\hline Lactose (\%) & 14,00 & 14,00 & 14,00 & 14,00 & 14,00 & 14,00 & 14,00 & 14,00 \\
\hline Lisina (\%) & 1,600 & 1,600 & 1,600 & 1,600 & 1,600 & 1,600 & 1,600 & 1,600 \\
\hline Metionina+cistina (\%) & 0,900 & 0,900 & 0,900 & 0,900 & 0,900 & 0,900 & 0,900 & 0,900 \\
\hline Metionina (\%) & 0,622 & 0,605 & 0,587 & 0,569 & 0,606 & 0,592 & 0,577 & 0,590 \\
\hline Treonina $(\%)$ & 1,020 & 1,020 & 1,020 & 1,020 & 1,020 & 1,020 & 1,020 & 1,020 \\
\hline Triptofano (\%) & 0,284 & 0,284 & 0,284 & 0,287 & 0,284 & 0,284 & 0,284 & 0,284 \\
\hline Cálcio (\%) & 0,850 & 0,850 & 0,850 & 0,853 & 0,850 & 0,850 & 0,850 & 0,850 \\
\hline Fósforo total (\%) & 0,800 & 0,800 & 0,800 & 0,806 & 0,800 & 0,800 & 0,800 & 0,800 \\
\hline Sódio (\%) & 0,630 & 0,630 & 0,630 & 0,630 & 0,630 & 0,630 & 0,630 & 0,630 \\
\hline Cloro (\%) & 0,460 & 0,460 & 0,460 & 0,497 & 0,460 & 0,460 & 0,460 & 0,460 \\
\hline Potássio (\%) & 0,864 & 0,769 & 0,674 & 0,577 & 0,819 & 0,775 & 0,731 & 0,830 \\
\hline
\end{tabular}

épocas de abate, oito tratamentos e quatro repetições. A interação época de abate e tratamento foi analisada através da ANOVA, e as médias dos fatores comparados pelo teste $\mathrm{F}$, com decomposição dos contrastes ortogonais ao nível de $5 \%$ de probabilidade. Para as avaliações dos parâmetros sangüíneos foi utilizado delineamento em blocos casualizados, com oito tratamentos e quatro repetições, considerando-se as idades de abate independentes ( 27 e 34 dias de idade).

\section{Resultados e Discussão}

As médias de peso absoluto (PA) e peso relativo $(\mathrm{PR})$ do pâncreas e da atividade da enzima tripsina (AT) dos leitões estão apresentadas na tabela 2. Não foi observada diferença significativa $(\mathrm{P}>0,05)$ para a interação entre idade e tratamento e efeito 
Tabela 2 - Peso absoluto do pâncreas (PA) em g, peso relativo (PR) em \% e atividade da tripsina (AT) em hmol/g de proteína nos leitões aos 21, 28 e 35 dias (d) de idade consumindo rações com leite em pó (LP), plasma suíno (PS), ovo inteiro (OI) e farelo de soja (FS)

\begin{tabular}{|c|c|c|c|c|c|c|c|c|c|c|c|}
\hline & $\mathrm{CT}^{* *}$ & LP & $\begin{array}{c}\text { PS } \\
25 \% *\end{array}$ & $\begin{array}{c}\text { PS } \\
50 \% *\end{array}$ & $\begin{array}{c}\text { PS } \\
75 \% *\end{array}$ & $\begin{array}{c}\mathrm{OI} \\
15 \% *\end{array}$ & $\begin{array}{r}\text { OI } \\
30 \% *\end{array}$ & $\begin{array}{c}\mathrm{OI} \\
45 \% *\end{array}$ & FS & Média*** & $\begin{array}{l}\mathrm{CV} \\
(\%)\end{array}$ \\
\hline PA & 6,63 & & & & & & & & & & \\
\hline $28 d$ & & 13,18 & 13,43 & 14,43 & 11,25 & 13,23 & 12,17 & 10,68 & 10,98 & $12,42 \mathrm{~B}$ & 17,3 \\
\hline $35 \mathrm{~d}$ & & 18,93 & 18,30 & 19,43 & 17,35 & 20,65 & 20,53 & 21,00 & 19,40 & $19,45 \mathrm{~A}$ & \\
\hline Média & & 16,05 & 15,86 & 16,93 & 14,30 & 16,94 & 16,35 & 15,84 & 15,19 & 15,93 & \\
\hline PR & 0,109 & & & & & & & & & & 15,7 \\
\hline $28 \mathrm{~d}$ & & 0,161 & 0,168 & 0,184 & 0,160 & 0,164 & 0,157 & 0,139 & 0,156 & $0,161 \mathrm{~B}$ & \\
\hline $35 \mathrm{~d}$ & & 0,163 & 0,174 & 0,181 & 0,181 & 0,198 & 0,190 & 0,189 & 0,175 & $0,179 \mathrm{~A}$ & \\
\hline Média & & 0,162 & 0,171 & 0,182 & 0,172 & 0,181 & 0,174 & 0,164 & 0,166 & & \\
\hline $\mathbf{A T}$ & 45,85 & & & & & & & & & & 41,0 \\
\hline $28 \mathrm{~d}$ & & 62,96 & 80,73 & 59,55 & 72,02 & 39,99 & 49,00 & 63,76 & 53,66 & $60,78 \mathrm{~B}$ & \\
\hline $35 \mathrm{~d}$ & & 89,47 & 86,73 & 114,98 & 122,77 & 107,47 & 87,81 & 126,35 & 125,18 & $108,08 \mathrm{~A}$ & \\
\hline Média & & 74,32 & 83,31 & 83,31 & 101,02 & 73,73 & 71,18 & 95,06 & 89,42 & 84,00 & \\
\hline
\end{tabular}

*\% de substituição da proteína do leite em pó.**CT - leitões testemunha abatidos no dia da desmama (21 dias de idade). *** - Efeito da idade: A, B médias na mesma coluna seguidas por letras distintas diferem entre si ao nivel de $5 \%$ de probabilidade pelo teste $\mathrm{F}$

dos tratamentos.

Foi observada diferença significativa $(\mathrm{P}<0,05)$ para idade, com aumento do PA e PR do pâncreas e da atividade da tripsina em razão do aumento da idade de abate. Estes dados concordam com Castillo Soto ${ }^{10}$ que também observaram aumento da atividade da tripsina com o aumento da idade de abate.

Makkink et al. ${ }^{4}$ verificaram aumento do peso do pâncreas dos leitões aos seis dias de idade, consumindo rações com concentrado protéico de soja e leite em pó, quando comparado aos animais consumindo ração com farelo de soja e também alteração da secreção de enzimas pancreáticas em razão das diferentes fontes de proteína: leite em pó, concentrado protéico de soja, farelo de soja e farinha de peixe. Lindemann et al. ${ }^{11}$ observaram decréscimo da atividade de enzimas digestivas com a utilização de fontes de proteína de origem vegetal.

Verificou-se uma tendência para aumento linear da AT com o aumento dos níveis de PS nas rações aos 35 dias de idade. De acordo com Lehninger ${ }^{12}$, a enzima tripsina é específica em sua ação; catalisa a hidrólise apenas das ligações peptídicas das quais participa a carboxila de resíduos de arginina e lisina, não importando o comprimento da cadeia ou sua seqüência de aminoácidos. O plasma é constituído por proteínas, as quais, por sua vez, são formadas em grande parte por resíduos de lisina e arginina. Uma vez que o consumo de ração dos leitões dos 21 aos 34 dias de idade, abatidos aos 35 dias foi semelhante, as alterações nas concentrações dos aminoácidos lisina e arginina, presentes na proteína do plasma com o aumento crescente deste na ração, podem justificar o aumento observado nos valores absolutos de atividade da tripsina no pâncreas dos animais consumindo rações com níveis crescentes de PS.

As médias dos parâmetros sangüíneos dos leitões estão apresentadas nas tabelas 3 e 4. As variações ocorridas nos valores absolutos dos parâmetros sangüíneos com o aumento da idade dos animais estão de acordo com os dados da literatura. ${ }^{13}$

Aos 27 dias de idade, observou-se diferença significativa $(\mathrm{P}<0,05)$ para o $\mathrm{C} 3$ sobre a concentração de leucócitos (LE) e volume globular (VG) e para o C8 sobre a concentração de hemácias (HE), LE e hemoglobina $(\mathrm{Hb})$. Enquanto aos 34 dias de idade observou-se efeito significativo $(\mathrm{P}<0,05)$ para o $\mathrm{C} 3$ sobre o número de $\mathrm{HE}$.

Não foi observada diferença entre a média dos parâmetros do hemograma dos animais consumindo rações com PS e a daqueles consumindo rações com OI. Estes dados concordam com os resultados de Figueiredo $^{2}$, que não observou alterações no hematócrito e nem na concentração de hemoglobina de leitões que após a desmama consumiram rações com OI substituindo a 
Tabela 3 - Hemácias (HE) em $\mathrm{mm}^{3} \times 10^{3}$, leucócitos (LE) em $\mathrm{mm}^{3}$, hemoglobina (HB) em $\mathrm{g} \%$ e volume globular (VG) em \% da hemoglobina, proteína total (PT) e albumina (Alb) em g/dL no sangue dos leitões, aos 21, 27 e 34 dias (d) de idade, consumindo rações com leite em pó (LP), plasma suíno (PS), ovo inteiro (OI) e farelo de soja (FS)

\begin{tabular}{|c|c|c|c|c|c|c|c|c|c|c|c|}
\hline & CT** & LP & $\begin{array}{c}\text { PS } \\
25 \% *\end{array}$ & $\begin{array}{c}\text { PS } \\
50 \% *\end{array}$ & $\begin{array}{c}\text { PS } \\
75 \% *\end{array}$ & $\begin{array}{c}\text { OI } \\
15 \% *\end{array}$ & $\begin{array}{c}\text { OI } \\
30 \% *\end{array}$ & $\begin{array}{c}\text { OI } \\
45 \% *\end{array}$ & FS & Média & $\mathrm{CV}(\%)$ \\
\hline HE & 6007 & & & & & & & & & & \\
\hline $27 \mathrm{~d}^{\mathrm{Cs}}$ & & 6643 & 6150 & 6288 & 6543 & 5935 & 6240 & 5880 & 6215 & 6282 & 8,83 \\
\hline $34 \mathrm{~d}^{\mathrm{C} 3}$ & & 6298 & 6515 & 6933 & 7020 & 6753 & 6683 & 6538 & 6828 & 6651 & 8,97 \\
\hline LE & 7382 & & & & & & & & & & \\
\hline $27 \mathrm{~d} \mathrm{c}^{\mathrm{C}}, \mathrm{Cs}$ & & 10075 & 8825 & 8075 & 8050 & 8025 & 9525 & 7625 & 8275 & 8728 & 14,85 \\
\hline $34 \mathrm{~d}$ & & 11000 & 12325 & 9125 & 11475 & 12700 & 14375 & 12900 & 11925 & 11869 & 27,12 \\
\hline HB & 12,02 & & & & & & & & & & \\
\hline $27 \mathrm{~d}^{\mathrm{C}} 3, \mathrm{Cs}$ & & 11,78 & 11,83 & 11,48 & 12,35 & 11,28 & 12,35 & 10,75 & 11,68 & 11,69 & 8,97 \\
\hline $34 \mathrm{~d}$ & & 11,78 & 12,45 & 12,78 & 12,53 & 12,25 & 12,05 & 11,95 & 12,40 & 12,22 & 12,06 \\
\hline VG & 39,20 & & & & & & & & & & \\
\hline $27 \mathrm{~d} \mathrm{C}^{\mathrm{C}}$ & & 36,48 & 37,98 & 38,15 & 40,00 & 36,93 & 39,05 & 37,20 & 37,90 & 37,79 & 7,40 \\
\hline $34 \mathrm{~d}$ & & 37,95 & 39,33 & 41,48 & 40,70 & 39,25 & 38,83 & 39,40 & 40,35 & 39,47 & 12,22 \\
\hline PT & 5,182 & & & & & & & & & & \\
\hline $27 \mathrm{~d}$ & & 5,02 & 4,99 & 5,06 & 4,95 & 4,95 & 4,76 & 4,76 & 5,01 & 4,95 & 7,43 \\
\hline $34 \mathrm{~d}$ & & 5,06 & 5,29 & 5,31 & 5,35 & 5,35 & 5,18 & 5,29 & 5,31 & 5,24 & 7,77 \\
\hline Alb & 3,418 & & & & & & & & & & \\
\hline $27 \mathrm{~d} \mathrm{Cl}^{\mathrm{Cl}}$ & & 3,37 & 3,67 & 3,41 & 3,55 & 3,44 & 3,34 & 3,30 & 3,05 & 3,39 & 9,66 \\
\hline $34 \mathrm{~d}$ & & 3,58 & 3,73 & 3,77 & 3,76 & 3,77 & 3,55 & 3,70 & 3,65 & 3,67 & 8,44 \\
\hline
\end{tabular}

* \% de substituição da proteína do leite em pó. **CT - leitões testemunha, sangue coletado no dia de desmama (21 dias de idade). Contrastes testados: C1: FS vs demais tratamentos; C2: Niveis de PS vs niveis de OI; C3: Regressão (Reg) linear PS; C4: Reg

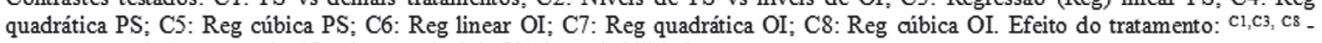
contraste estatisticamente significativo ao nível de $5 \%$ de probabilidade

Tabela 4 - Contagem diferencial dos leucócitos em percentagem: eosinófilos (EOS), neutrófilos bastonetes (NB), neutrófilos segmentados (NS), linfócitos (LINF) e monócitos (MON) no sangue dos leitões, aos 21, 27 e 34 dias de idade, consumindo rações com leite em pó (LP), plasma suíno (PS), ovo inteiro (OI) e farelo de soja $(\mathrm{FS})$

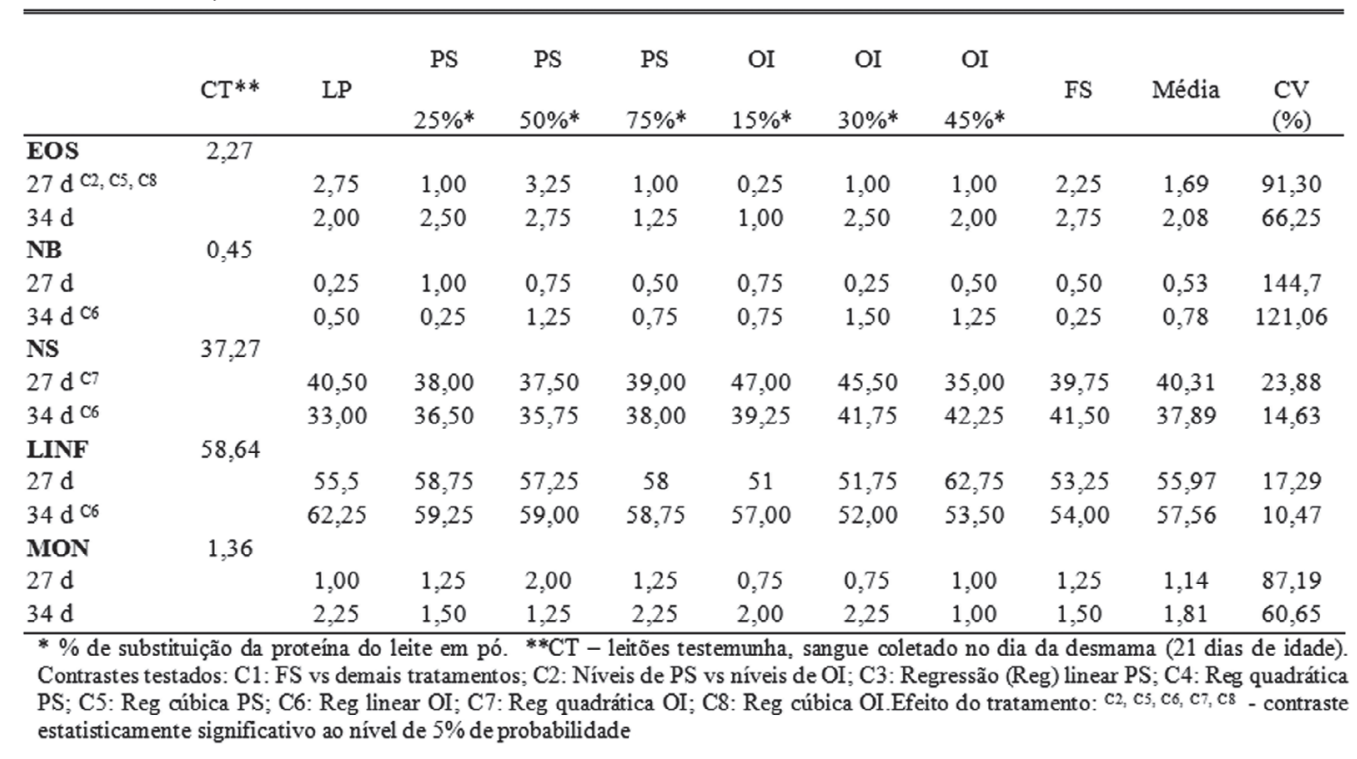


PB do plasma sangüíneo em até 100\%.

A utilização de níveis crescentes de PS, em substituição parcial à PB do LP, promoveu redução linear na concentração de LE e aumento linear do VG do sangue dos leitões aos 27 dias de idade, conforme as equações $\mathrm{LE}=9780-27,300 \mathrm{X}\left(\mathrm{R}^{2}=0,86\right)$ e $V G=36,5375+0,04300 X\left(R^{2}=0,92\right)$, respectivamente (Figuras 1 e 2 ). A redução no número de leucócitos confirma o efeito do PS sobre a defesa humoral do organismo, indicando menor ativação do sistema imune nos leitões.

Verificou-se aumento linear na concentração de HE no sangue dos leitões aos 34 dias de idade, com o aumento dos níveis de PS na ração, conforme equação $\mathrm{HE}=6303,5+10,340 \mathrm{X}\left(\mathrm{R}^{2}=0,95\right)($ Figura 3).

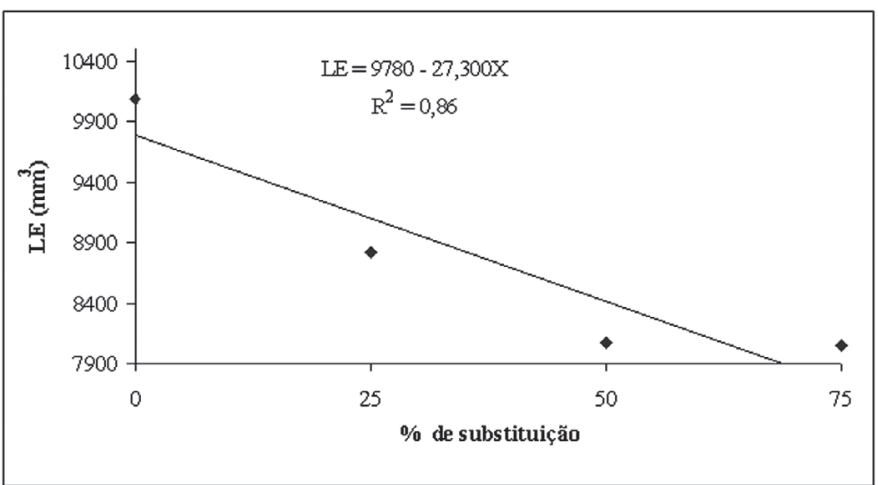

Figura 1 - Níveis de substituição da PB do LP pela PB do PS na ração sobre o número de leucócitos (LE) no sangue dos leitões, aos 27 dias de idade

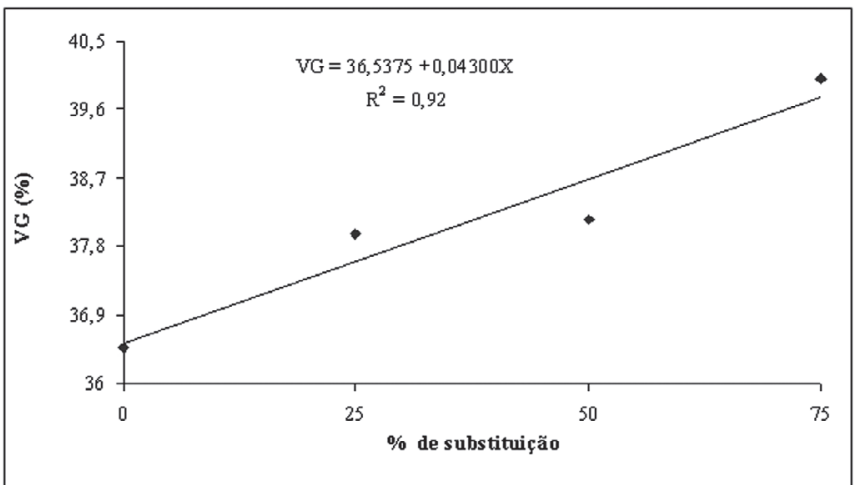

Figura 2 - Níveis de substituição da PB do LP pela PB do PS na ração sobre o volume globular (VG) no sangue dos leitões, aos 27 dias de idade

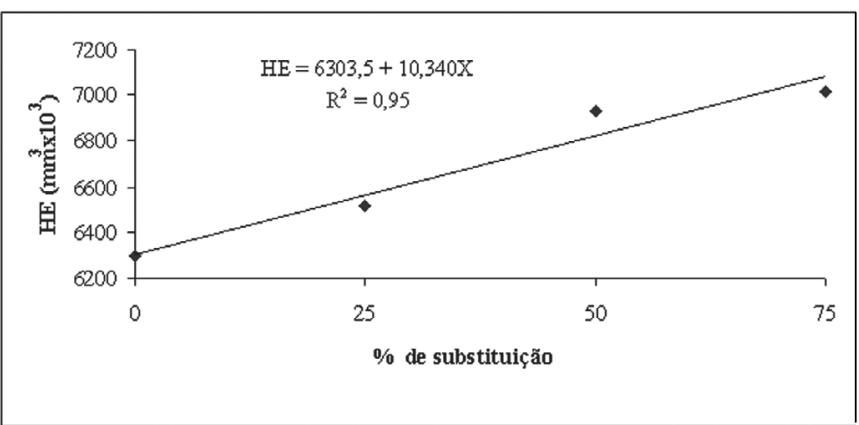

Figura 3 - Níveis de substituição da PB do LP pela PB do PS na ração sobre o número de hemácias (HE) no sangue dos leitões, aos 34 dias de idade 
Estes dados discordam de Jiang et al. ${ }^{14}$ que não verificaram alteração na concentração dos leucócitos no sangue de leitões consumindo rações com $6 \%$ de PS, quando comparados àqueles consumindo ração com 10\% de LP + 7\% de farinha de peixe; mas observaram redução $d a$ infiltração local de leucócitos na mucosa da lâmina própria intestinal, com a utilização de PS na ração.

O aumento verificado para a hemoglobina e o volume globular dos leitões, aos 27 dias de idade, e para o número de eritrócitos, dos leitões aos 34 dias de idade, confirma a suposição de que o PS utilizado nas rações continha alta concentração de ferro. A utilização do citrato de sódio como anticoagulante durante o processo de produção do plasma por "spray-drier", pode interferir no processo de absorção uma vez que este aumenta a eficiência de absorção do ferro dietético. ${ }^{15}$

A utilização de níveis crescentes de OI, em substituição parcial à PB do LP influenciou cubicamente as concentrações de LE e Hb nos leitões aos 27 dias de idade, conforme as equações $\mathrm{LE}=10075$ $409,44 \mathrm{X}+23,333 \mathrm{X}^{2}-0,3432 \mathrm{X}^{3}\left(\mathrm{R}^{2}=1,00\right)$, $\mathrm{Hb}=11,775-0,1803 \mathrm{X}+\quad 0,0129 \mathrm{X}^{2}-$ $0,0002 X^{3}\left(R^{2}=1,00\right)$.

Quanto a contagem diferencial de leucócitos, aos 27 dias de idade, observouse diferença significativa $(\mathrm{P}<0,05)$ para o $\mathrm{C} 2$, e efeito significativo $(\mathrm{P}<0,05)$ do $\mathrm{C} 5$ e C8 sobre a percentagem de eosinófilos (EOS) e do C7 sobre a percentagem de neutrófilos segmentados (NS). Aos 34 dias de idade, verificou-se efeito significativo $(\mathrm{P}<0,05)$ para o $\mathrm{C} 6$ sobre a percentagem de neutrófilos bastonetes (NB), neutrófilos segmentados (NS) e linfócitos (LINF).

Os animais, consumindo rações com PS, apresentaram na média, maior percentagem de EOS quando comparados aos leitões consumindo rações com OI. Segundo Matos e Matos ${ }^{13}$, a função primordial dos eosinófilos é combater substâncias tóxicas, estando presentes em maior concentração nos locais onde ocorrem reações antígenoanticorpo e nos pontos de penetração de substâncias estranhas ao organismo, e em menor quantidade na corrente circulatória em situações de estresse, reaparecendo no período de recuperação. Desta forma, uma maior concentração de EOS na corrente sangüínea dos leitões consumindo PS sugere menor ativação do sistema imunológico. A menor concentração de EOS na circulação sangüínea dos leitões consumindo rações com OI indica que, de alguma forma, a utilização de OI pode ter promovido maior resposta ao sistema humoral dos animais.

A utilização de níveis crescentes de PS influenciou cubicamente a percentagem de EOS no sangue dos leitões aos 27 dias de idade, conforme a equação EOS=2,75$0,2633 \mathrm{X}+0,01 \mathrm{X}^{2}-0,00009066 \mathrm{X}^{3} \quad\left(\mathrm{R}^{2}\right.$ $=1,00)$, enquanto que a utilização de níveis crescentes de OI, em substituição parcial à $\mathrm{PB}$ do LP, promoveu resposta cúbica sobre a percentagem de EOS e resposta quadrática sobre a percentagem de NS, conforme as equações EOS $=2,75$ $0,3639 \mathrm{X}+0,0161 \mathrm{X} 2-0,0002 \mathrm{X} 3(\mathrm{R} 2=1,00)$ e NS $=40,45+0,7 \mathrm{X}-0,0189 \mathrm{X} 2(\mathrm{R} 2=0,99)$, (Figura 4). Foi estimada uma concentração máxima de 49,3\% de NS quando o OI substituiu $18,5 \%$ da PB do LP.

Aos 34 dias de idade, a utilização de níveis crescente de OI, em substituição parcial à $\mathrm{PB}$ do LP, promoveu aumento linear sobre a percentagem de NB e NS, e redução linear na percentagem de LINF, conforme as equações $\mathrm{NB}=0,55+0,02 \mathrm{X}$ $\left(\mathrm{R}^{2}=0,72\right), \mathrm{NS}=34,525+0,201667 \mathrm{X}$ $\left(\mathrm{R}^{2}=0,84\right)$ e $\mathrm{LINF}=60,875-0,208333 \mathrm{X}$ $\left(\mathrm{R}^{2}=0,79\right)$, (Figuras 5, 6 e 7).

As alterações na contagem diferencial dos leucócitos dos leitões consumindo rações com OI confirmam que estes animais tiveram seu sistema imune ativado em maior proporção.

No proteinograma verificou-se efeito significativo $(\mathrm{P}<0,05)$ para o $\mathrm{C} 1$ sobre a concentração de albumina (ALB) nos leitões com 27 dias. A média da concentração de ALB nos leitões com 27 


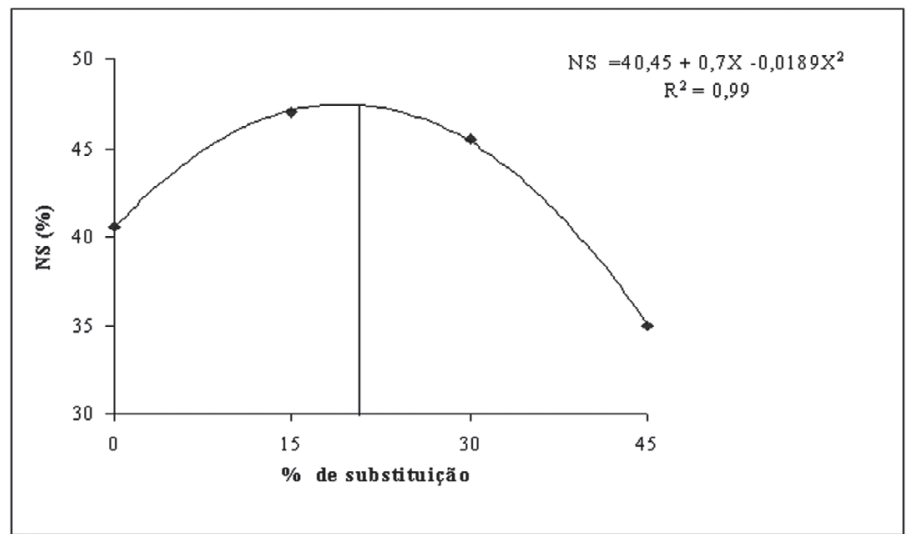

Figura 4 - Níveis de substituição da PB do LP pela PB do OI na ração sobre a percentagem de neutrófilos segmentados (NS) no sangue dos leitões, aos 27 dias de idade

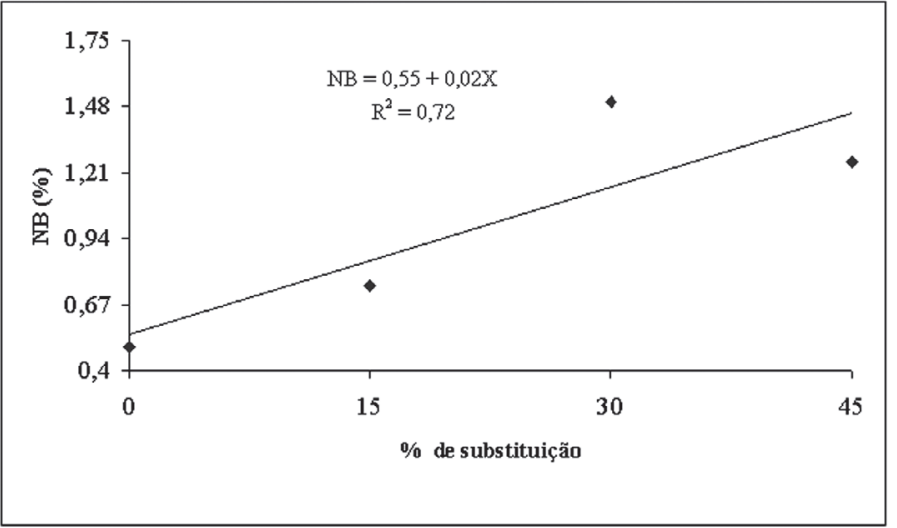

Figura 5 - Níveis de substituição da PB do LP pela PB do OI na ração sobre a percentagem de neutrófilos basófilos (NB) no sangue dos leitões, aos 34 dias de idade

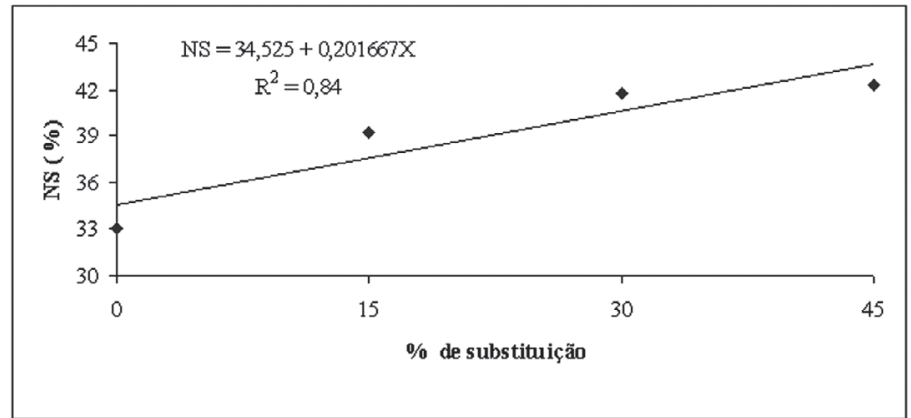

Figura 6 - Níveis de substituição da PB do LP pela PB do Ol na ração sobre a percentagem de neutrófilos segmentados (NS) no sangue dos leitões, aos 34 dias de idade 


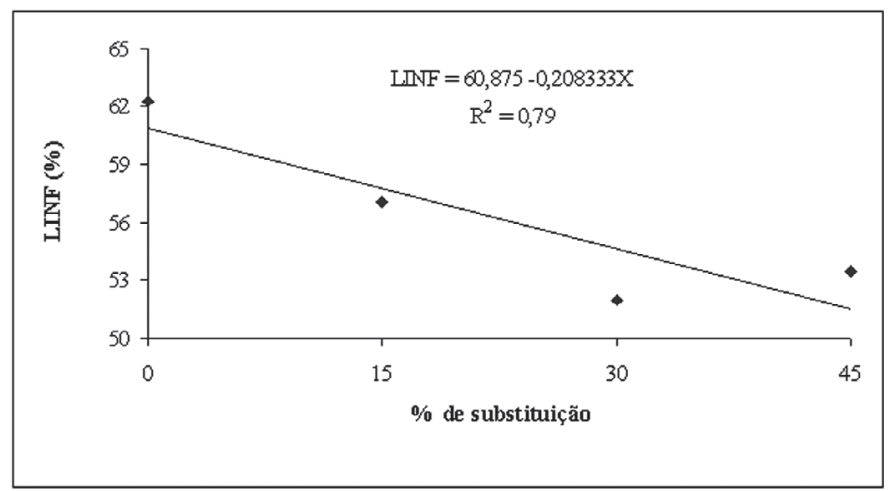

Figura 7 - Níveis de substituição da PB do LP pela PB do OI na ração sobre a percentagem de linfócitos (LINF) no sangue dos leitões, aos 34 dias de idade

dias e consumindo ração FS foi inferior à média dos demais tratamentos. Estes resultados podem estar associados ao menor consumo de ração dos leitões desse tratamento na primeira semana, reduzindo o aporte de aminoácidos necessários para a síntese de ALB.

Embora os tratamentos tenham influenciado significativamente os parâmetros sangüíneos, os valores encontrados para hemograma e leucograma estão dentro da normalidade, concordando com aqueles citados por Swenson ${ }^{15}$; Matos e Matos ${ }^{13}$ e Ribeiro ${ }^{16}$.

\section{Conclusões}

A substituição da proteína do plasma suíno e do ovo inteiro pela proteína do leite em pó em até 75 e 45\%, respectivamente, na ração de leitões recém desmamados não influenciaram o peso do pâncreas e a atividade da tripsina pancreática.

A utilização de plasma suíno promoveu menor estímulo à resposta imune, enquanto que a utilização de ovo inteiro promoveu maior resposta humoral dos leitões.

\section{Different protein sources in rations of piglets on activity of trypsin and blood parameters}

\section{Abstract}

Were used 64 piglets submitted eight treatments: ration with skim milk (SM), three rations with crescent levels of swine plasma (SP), three rations with whole egg (WE) and a ration with high inclusion of soybean meal (SB). Were monitored the blood parameters (BP) in pigs at 27 and at 34 days of age. The piglets were slaugther at 28 and at 35 days of age, for collections pancreas and posterior mensurements of absolut (AW) and relative weigth (RW) of pancreas and trypsin activity (TA). Treatments not influencied AW and TA. Significant effect of the crescent levels was verified of SP, with lineal reduction of the leukocytes and increase of the globular volume, to the 27 days; while to the 34 days, lineal increase of the hematias was observed. At 27 days, animals feds rations with crescent levels of SP have inferior percentage of eosinophils than others that consumed crescent levels of WE. The utilization of SP promoted smaller stimulus to the immune reply, while the use of WE promoted larger humoral reply of the piglets.
Key words:

Digestive enzyme. Hematia.

Leukocyte.

Nutrition.

Swine. 


\section{Referências}

1 BUTOLO, E. F.; MYADA, V. S.; PACKER, I. U.; MENTEN, J. F. M. Uso de plasma suíno desidratado por "spray-drier" na dieta de leitões desmamados precocemente. Revista Brasileira de Zootecnia, v. 28, n. 2, p. 326-333, 1999.

2 FIGUEIREDO, A. O ovo em pó na alimentação de leitões recém-desmamados. 2002. 61 f. Dissertação (Mestrado em Zootecnia), Escola Superior de Agricultura "Luiz de Queiroz", Universidade de São Paulo, Piracicaba. 2002.

3 VAN DIJK, A. J.; EVERTS, H.; NABUURS, M. J. A.; MARGRY, R. J. C. F.; BEYNEN, A. C. Growth performance of weanling pigs fed spray-dried animal plasma: a review. Livestock Production Science, v. 68 n. 2/3, p. 263-274, 2001.

4 MAKKINK, C. A.; BERNTSEN, P. J.; KAMP, B. M.; KEMP, B.; VERSTEGEN, M. W. Gastric protein breakdown and pancreatic enzyme activities in response to two dietary protein sources in newly weaned pigs. Journal of Animal Science, v. 72, n. 11, p. 2843-2850 1994.

5 COFFEY, R. D.; CROMWELL, G. L. The impact of environment and antimicrobial agents on the growth response of early-weaned pigs to spray-dried porcine plasma. Journal of Animal Science, v. 73, n. 9, p. 2532 2539, 1995.

6 HARMON, B. G.; LATOUR, M. A.; DURST, J. Spraydried eggs as an ingredient in diet for sew pigs. In: PURDUE UNIVERSITY. Purdue University swine day report 2000 . Disponível em: <http:// www.ansc.purdue.edu/swine/swineday/sday00/psd032000.html > . Acesso em 03 fev. 2005.

7 NATIONAL RESEARCH COUNCIL. Nutrient requirements of swine. 10. ed. Washington, D.C.: National Academy Press, 1998. 189 p.

8 KAKADE, M. L.; RACKIS, J. J.; MCGHEE, J. E.; PUSKY, G. Determination of trypsin inhibitor activity of soy products. A collaborative analysis of and improved method. Cereal Chemistry, v. 51, n. 3, p. 376-382, 1974.

9 HARTREE, E. F. Determination of protein: a modification of lowry method that gives a linear photometric response. Analytical Biochemical, v. 48 n. 2, p. 422-427, 1972.

10 CASTILLO SOTO, W. L. Digestibilidade da levedura desidratada (Saccharomyces cerevisiae) e efeitos da sua utilização sobre a morfologia intestinal, atividade das enzimas digestivas e desempenho de suínos. 1999. 82 f. Tese (Doutorado) - Faculdade de Ciências Agrárias e Veterinárias, Universidade Estadual Paulista, 1999.

11 LINDEMANN, M. D.; CORNELIUS, S. G.; EL KANDELGY, S. M.; MOSER, R. L.; PETTIGREW, J. E. Effect of age, weaning and diet on digestive enzyme levels in the piglet. Journal of Animal Science, v. 62, n. 5, p. 1298-1307, 1986.

12 LEHNINGER, A. L. Princípios de bioquímica. São Paulo: SARVIER, 1984. 681 p.

13 MATOS, M. S.; MATOS, P. F. Laboratório clínico médico-veterinário. 2. ed. Rio de Janeiro: Atheneu, 1988. 238 p.

14 JIANG, R.; CHANG, X.; STOLL, B.; FAN, M. Z.; ARTHINGTON, J.; WEAVER, E.; CAMPBELL, J.; BURRIN, D. G. Dietary plasma protein reduces small intestinal growth and lamina propria cell density in early weaned pigs. Journal of Nutrition, v. 130, n. 1, p. 21-26, 2000.

15 SWENSON, M. J. Propriedades fisiológicas e constituintes celulares e químicos do sangue. In: SWENSON, M. J. (Ed.). Dukes fisiologia dos animais domésticos. 10. ed. Guanabara Koogan: Rio de Janeiro, 1984. p. 13-34.

16 RIBEIRO, P. R. Efeitos da adição de betaína, na ração de suínos, sobre a incidência de diarréia, desempenho e características de carcaça. 2000. $66 \mathrm{f}$. Tese (Doutorado em Zootecnia). Faculdade de Ciências Agrárias e Veterinárias, Universidade Estadual Paulista, 2000. 